[Beautrais, A. (1996). Youth Suicide. New Zealand Annual Review of Education, 5, 3-21]

\section{Youth Suicide}

\section{ANNETTE BEAUTRAIS}

\section{Abstract:}

Youth suicide rates have increased markedly in New Zealand during the last three decades and are now among the highest in the developed world. Major risk factors for suicidal behaviour include: psychiatric illness (notably, depressive disorders, substance abuse disorders and antisocial behaviours) previous suicide attempts and comorbid diagnoses of more than one mental disorder; exposure to adverse childhood and family experiences; social disadvantage; borderline and antisocial personality disorders; genetic and biologic factors. The best hope for substantial reduction in youth suicide rates may lie in reducing the number of young people with mental disorders. There is substantial scope for schools to participate in inter-sectoral efforts to promote and improve youth mental health in order to reduce vulnerability to mental disorders associated with suicidal behaviour.

n New Zealand, as in many countries, there have been marked increases in rates of youth suicide during the last three decades and, internationally, New Zealand now has one of the highest rates of youth suicide among developed countries (World Health Organisation, 1993). In New Zealand suicide accounts for one in four deaths amongst young males aged 15-24 years and is the second leading cause of death, after motor vehicle accidents, for males of this age (New Zealand Health Information Service, 1995b).

In parallel with completed suicide, rates of attempted suicide among youth appear to have increased. Together, completed and attempted suicide are a seemingly preventable source of mortality and morbidity among young people.

This paper reviews suicidal behaviour, including both nonfatal suicide attempts and completed suicide, in young people. The age range considered includes the periods of early adolescence (10-14 years), middle adolescence (15-19 years) and late adolescence to early adulthood (20-24 years). The paper discusses characteristics, risk factors
4 Annette Beautrais

and trends associated with youth suicidal behaviour, and comments about strategies to prevent suicide in young people.

\section{Epidemiology of Suicide and Attempted Suicide}

Suicide

Recent international data indicate that New Zealand has high rates of youth suicide. The World Health Statistics Annual for 1993 showed that in 1991, the year for which data were most recently available, New Zealand had the highest rate of suicide for males aged 15-24 years among a series of 14 industrialised countries. In that year the agespecific suicide rate for New Zealand males aged 15-24 years was 38.7 per 100000 population. In comparison, Australia (26.6), the United States of America (22.0), the United Kingdom (12.2) and Japan (9.1) all had significantly lower suicide rates.

Whilst, almost universally, female rates of suicide are much lower than those for males, New Zealand in 1991 also recorded the highest suicide rates for females aged 15 to 24 years, with an age specific rate of 6.7 per 100000 population. Comparative rates in Australia (6.2), Japan (4.7), the United States of America (3.9) and the United Kingdom (2.3) were all lower than in New Zealand.

Recent data, from 1987 to 1993, suggest that rates of youth suicide in New Zealand have remained relatively stable. However, other countries including Denmark, Japan, Germany and Switzerland have recorded reductions in youth suicide rates from the mid 1980s to the early 1990s.

\section{Attempted suicide}

Suicide attempts span a range of behaviours from those which do not come to public attention to those which require hospital admission. In general, suicide attempt data are less well recorded than actual suicides, and less information is available about attempted suicide than about completed suicide.

Community surveys of high school students in a number of countries have estimated rates of attempted suicide among adolescents that range from $3 \%$ to $10 \%$ of the population (Andrews and Lewinsohn, 1992; Dubow et al., 1989; Joffe et al., 1988; Meehan et al., 1992; Smith and Crawford., 1986). In New Zealand, a longitudinal study of the development of suicidal behaviours in a birth cohort of 954 children showed that, by 16 years, $12 \%$ of this cohort reported suicidal ideation and $3 \%(4.2 \%$ of females and $1.9 \%$ of males) reported having made a suicide attempt (Fergusson and Lynskey, 1995). 
New Zealand statistics for hospitalisations following suicide attempts show that, in 1993, the rate of such hospitalisations for under15 year olds was relatively low (17.6 per 100 000) but increased substantially for $15-19$ year olds (234.8 per 100000$)$ and for 20-24 year olds (211.2 per 100 000) (New Zealand Health Information Service, 1995a).

While there are undoubted differences between the populations of those who die by suicide and those who make nonfatal suicide attempts, emerging research evidence suggests many more similarities than differences between these two groups (Spirito et al., 1989). Therefore, for the purpose of this review, the characteristics of both suicide attempts and completed suicide will be examined together as "suicidal behaviour"

\section{Method}

Methods of suicide vary by gender and between countries depending, in part, upon availability and preference for particular methods. In New Zealand in 1993 hanging was the most common method of suicide for under 25 year olds $(43.4 \%)$, with the next most common methods being carbon monoxide poisoning (30.0\%), gunshot (11.6\%) and drug overdose (7.8\%) (New Zealand Health Information Services, 1995b).

By contrast, the clear majority of nonfatal suicide attempts are by drug overdose. Data from the Canterbury Suicide Project, which examined the methods used by 129 young people aged under 25 years who were hospitalised with serious, but nonfatal, suicide attempts, showed that most medically serious suicide attempts (76.7\%) were made by drug overdose.

\section{Risk Factors for Suicidal Behaviour}

It is now well acknowledged that there is not a single cause for suicidal behaviour; rather, there are multiple causes and these are related in a complex manner (Diekstra et al., 1995; Moscicki, 1995; Piacentini and Shaffer, 1994).

A series of psychological autopsy studies within the last decade has collected detailed information on the antecedents, correlates and risk factors associated with both completed suicide and nonfatal suicide attempts among young people. The "psychological autopsy" approach attempts to reconstruct retrospectively the background and circumstances of each suicide by interviewing family, friends, teachers and health professionals and reviewing the range of contributing factors. The results of these studies suggest, broadly, that there is a range of predisposing factors which may render an individual vulnerable to suicidal behaviour. In such vulnerable individuals the occurrence of a stressful life event may then precipitate a suicide attempt.

The recent literature on youthful suicidal behaviour suggests several major domains of predisposing, or risk, factors.

\section{Sociodemographic Risk Factors}

Age

International data suggest suicide among children and young adolescents up to the age of 15 years is rare, with the incidence of suicide increasing during the late teenage years and early 20 s. New Zealand data are consistent with these observations. In 1993 there were three suicides among under- 15 year olds, 40 suicides among 15-19 year olds, with twice as many (86) among 20-24 year olds.

Suicide attempt data show a different pattern, with 15-19 year olds more likely to be hospitalised following suicide attempts $(48.4 \%$ of all under-25 year old suicide attempt admissions) than under-15 year olds $(10 \%)$ or $20-24$ year olds $(41.6 \%)$ (New Zealand Health Information Service, 1995a, 1995b).

\section{Gender}

In New Zealand, as in North America, Europe and Australia, recent increases in youth suicide have occurred primarily among males. In 1993 in New Zealand, two of the three under- 15 year old suicides were male, and the clear majority of suicides among those aged 15-19 (83.7\%), and aged $20-24(88.4 \%)$ were male. However, more females than males are admitted to hospital following suicide attempts. In New Zealand almost two thirds (64.1\%) of such admissions for under-25 year olds in 1993 were females (New Zealand Health Information Service, 1995a, 1995b).

\section{Ethnicity}

Cultural differences in suicide rates have been widely reported but have generally been poorly explained. In New Zealand, Maori suicide rates have traditionally been significantly lower than non-Maori rates. However, within the last decade, rates of suicide among young Maori aged 15-24 years have increased, in parallel with those for all young New Zealanders, to levels similar to those for non-Maori (Skegg et al., 1995). These changes in Maori youth suicide rates are paralleled in the United States by recent changes in suicide rates among young African American and other minority males (Shaffer et al., 1994). Previously suicide rates for this group had been both lower and more stable than rates for young white males, but since the mid-1980s rates have 
increased markedly to now converge to the same suicide rates as those for young white males.

\section{Sociodemographic disadvantage}

New Zealand and overseas studies have reported higher rates in a range of indicators of social disadvantage among those individuals with suicidal behaviour, when compared with nonsuicidal control subjects (Beautrais et al., in press; Dubow et al., 1989; Heikkinen, 1995; Petronis et al., 1990; Platt and Kreitman, 1984; Sainsbury, 1986). These factors include higher rates of residential mobility, lower per annum income, and poor or no educational qualifications.

\section{Unemployment}

Unemployment is frequently speculated to be one of the causative factors for youth suicide. Many (but not all) examinations of aggregate (regional or national) data have shown positive associations between unemployment and both completed suicide and nonfatal suicide attempts (e.g., Diekstra, 1989; Platt and Kreitman, 1984; Sainsbury, 1981). In addition, a number of studies of individual subjects have suggested that rates of unemployment are elevated amongst those who die by suicide or make suicide attempts (Hawton and Rose, 1986; Heikkinen et al., 1995; Shepherd and Barraclough, 1980). However, whilst associations between unemployment and suicidal behaviour have consistently been documented, the role of unemployment as a causative factor for suicidal behaviour remains unclear. A recent analysis from the Canterbury Suicide Project examined the association between unemployment and serious suicide attempts in a sample of individuals who had made such attempts. The results of this analysis suggested that, to a substantial degree, the correlation between unemployment and serious suicide attempts was likely to reflect the presence of common or correlated antecedent factors, including, for example, adverse childhood experiences or prior history of psychiatric disorder, which contribute to risks of both unemployment and suicidal behaviour. However, the analysis also suggested that unemployment may play some contributory role in suicidal behaviour by acting as a short-term life event which may provoke suicidal behaviour in vulnerable individuals.

\section{Psychiatric Risk Factors}

Major psychiatric disorders play an important role in youth suicidal behaviour. Psychological autopsy studies have consistently reported that approximately $90 \%$ of those young people who die by suicide have a mental disorder at the time of their death (Brent et al., 1993; Lesage et al., 1994; Martunnen et al., 1991; Runeson, 1989; Shaffer and Piacentini, 1994; Shafii et al., 1985). Similarly, the recent literature on attempted suicide also suggests a high incidence of psychiatric disorder among young people who make suicide attempts (Andrews and Lewinsohn, 1992; Beautrais et al., in press; Brent et al., 1988; Fergusson and Lynskey, 1995).

The most common psychiatric disorders in young people with suicidal behaviour are affective (mood) disorders (including depressive illness and bipolar (manic depressive) disorders), substance use disorders (including alcohol, cannabis and other drug abuse or dependency) and antisocial behaviours (including adjustment disorders, conduct disorder and antisocial personality disorder). Although they occur less frequently, psychotic disorders (including schizophrenia), eating disorders (including anorexia and bulimia) and anxiety disorders have also been associated with suicidal behaviour.

\section{Comorbidity}

Recent research findingsindicate that comorbidity (the co-occurrence of more than one mental disorder at any one time) is common among individuals with suicidal behaviour. Comorbid diagnoses of depression, substance use disorders and/or antisocial personality disorder may be particularly important in determining vulnerability to suicidal behaviour (Brent et al., 1988; Martunnen et al., 1991).

\section{Previous suicide attempts}

One of the most specific risk factors for subsequent suicidal behaviour is a history of previous suicide attempt (Shaffer, 1988a). Among 129 young people in the Canterbury Suicide Project who had made a medically serious suicide attempt, $53.5 \%$ had made previous suicide attempts, compared to only $5.9 \%$ of nonsuicidal control subjects (Beautrais et al., in press).

\section{Personality Disorders, Personality Traits and Cognitive Style}

For adolescents as for adults, the personality disorders most closely associated with suicide are borderline personality disorder and antisocial personality disorder. In addition, particular personality traits including impulsiveness, angry or aggressive behaviour, social withdrawal, hypersensitivity and perfectionistic tendencies have been associated with suicidal behaviour in young people (Frances et al., 1986; Shaffer, 1974). 
Some researchers believe that cognitive style (the way in which an individual perceives, mentally organises and understands life experiences) is related to suicidal behaviour. Cognitive variables associated with suicidal behaviour include tendencies to think in a relatively inflexible or rigid fashion; to have poor problem solving ability; to be present-, rather than future-oriented; and to have a negative or hopeless outlook (Becket al., 1974; Frances, 1986; Neuringer, 1974; Patsiokas et al., 1979). However, the present evidence linking cognitive dysfunction with suicidal behaviour is weak (Diekstra et al., 1995).

\section{Psychosocial and Environmental Risk Factors}

\section{Family characteristics and childhood experiences}

Family characteristics and childhood experiences appear to be important risk factors for suicidal behaviour in young people. Results from two recent New Zealand studies are consistent with a large number of overseas studies in showing that children from disadvan-taged or dysfunctional family backgrounds, characterised by poor parental care, poor parental relationship, parental psychopathology, exposure to physical or sexual abuse, economic disadvantage and high residential mobility were at higher risk of suicidal behaviour than nonsuicidal control subjects (Beautrais et al., in press; Fergusson and Lynskey, 1995).

\section{School problems}

Although school problems, including deteriorating academic performance, disciplinary problems and truancy, have consistently been identified in the histories of children and adolescents with suicidal behaviour, these problems are not specifically associated with suicidal individuals and can occur in other adolescents who are emotionally troubled without being suicidal (Farberow, 1991). Therefore school problems, in and of themselves, are unlikely to be useful indicators of suicide risk unless identified in conjunction with suicide-specific risk factors.

\section{Social support}

Several studies have reported that a perceived lack of social support, particularly parental support, is a risk factor for suicidal behaviour among adolescents. (D'Attilio et al., 1992, Kienhorst et al., 1992).

\section{Life events}

Many incidents of suicidal behaviour are preceded by recent, stressful life events, and such life events are more likely to occur among those who attempt suicide than amongst non-suicidal control subjects (Shaffer, 1988a; Brent et al., 1988). Commonly identified life stresses which precede suicidal behaviour in adolescents include relationship, financial, legal or disciplinary problems (Rich et al., 1988; Shaffer, 1974). However, these life events occur to many young people, and they may act as precipitating factors for suicidal behaviour only when they occur in individuals who are vulnerable to such suicidal behaviour.

\section{Imitative behaviour}

There is increasing evidence that vulnerable individuals may imitate suicidal behaviour, and that this may occur following the suicide of someone known to the subject, or after fictional or documentary reports of suicidal behaviour. It appears that adolescents may be more vulnerable than adults to imitative suicidal behaviour (Gould, 1990; Hazell, 1993).

\section{Genetic and Biologic Risk Factors}

Genetic factors have been associated with suicidal behaviour but it is not clear whether what is being transmitted is a genetic predisposition to suicide per se or a genetic vulnerability to psychiatric disorders with which suicide is associated. There is clear evidence that psychiatric disorders, including schizophrenia, alcohol dependence and bipolar I disorder, which have a high risk of suicidal behaviour, are genetically transmitted (Kety, 1986; Roy, 1983). Adoption studies, which show an elevated risk of suicide in the biologic relatives of adoptees who die by suicide compared to nonsuicide control adoptees, provide some evidence of genetic transmission of a genetic factor for suicide (Roy et al., 1991)

A family history of suicide has been observed in a series of studies, and may arise either from a common biological vulnerability to suicide or psychiatric disorders with which suicide is associated, or through a shared family environment which is linked to adversity and disadvantage, which are themselves risk factors for suicide.

It has been argued (Asberg, 1986) that declining or low stable levels of the serotonin metabolite 5-HIAA occur more frequently in the cerebrospinal fluid (CSF) of individuals who attempt suicide or who die by suicide than in non-suicidal control subjects. Although little is known of the processes by which serotonin and suicidal behaviour might be 
linked, there is some evidence to suggest that impulsiveness and aggressive behaviour may be important intervening variables (Asberg, 1986; Mann et al., 1986).

\section{Explanations of Trends in Suicidal Behaviour}

Several possible explanations for recent changes in youth suicide rates have been proposed. These include: increased prevalence rates of depressive disorders, substance use disorders and antisocial behaviours in young people; lengthening of the period of social dependency; increased exposure to the media which provide models for suicidal behaviour; increases in unemployment among young people; the rise of a "youth culture"; increases in divorce rates; changes in family structure; changes in economic activity; and increasing urbanisation.

While it seems possible that increases in rates of psychiatric disorders associated with suicidal behaviour might contribute to increased youth suicide rates, it is less likely, as Diekstra et al. (1995) comment, that the social conditions suggested as explanatory variables are able to account for such rises, since these social conditions are poorly related to the risk factors which have been identified as being causally related to suicide risk.

\section{Prevention Strategies for Youth Suicide}

Major risk factors for suicidal behaviour have been identified and should be used to direct the development of suicide prevention and intervention programmes. The diversity of risk factors which have been shown to be associated with suicidal behaviour implies that simple and single interventions will not impact significantly on suicide rates.

It appears that youth suicide may be accounted for by complicated sets of risk factors which individually have a small impact on suicidal behaviour but which collectively make a substantial contribution to suicide risk. What is likely to be effective, therefore, is a series of intervention and prevention strategies targeted at high risk populations and operating in concert over a protracted period of time. The aim of this approach is to change the psychiatric, individual, family and social ecologies which appear to collectively contribute to suicide risk.

Many different approaches to youth suicide prevention have been developed, and these fall into several main categories:

\section{Early intervention}

There is considerable support for early intervention and family support programmes which attempt to reduce the number of children exposed to unsatisfactory or disadvantaged childhoods by improving parenting practices, ameliorating childhood adversity and increasing life opportunities (Garland and Zigler, 1993; Price et al., 1989). Such programmes targeted at high risk families might act to decrease risk of subsequent suicidal behaviour by reducing individual vulnerability to a broad range of adverse outcomes, including suicidal behaviour and the development of psychiatric morbidity with which suicidal behaviour is associated. Although there is considerable empirical support for the effectiveness of early intervention programmes, there is a need for ongoing evaluation, particularly with respect to assessing their impact on suicidal behaviour.

\section{Mental Health Care and Education}

Perhaps the best opportunity for intervention involves efforts to improve the recognition and treatment of adolescent mental health problems, notably affective disorders, substance use disorders and antisocial behaviours, and to improve delivery of mental health care to adolescents. A series of strategies have been proposed in the area of mental health which aim:

1. To better inform and educate the public about mental health issues and make appropriate treatment for mental illnesses more readily accepted by the public and by those with such illnesses;

2. To provide education programmes for teachers, counsellors, health care workers and associated professionals which focus on increasing awareness of the extent of affective and substance abuse disorders, and, in particular, offer guidelines for the better recognition, treatment and management of depression in young people;

3. To improve the organisation and structure of mental health care delivery systems, including both inpatient facilities and outpatient community based services. This approach implies the provision of adequate specialised mental health services for young people;

4. To provide appropriate therapy, follow-up and treatment of those individuals who have made suicide attempts, who are known to be at high risk of further suicidal behaviour. 


\section{School-based prevention programmes}

Community-based suicide prevention programmes have been developed in many places. Typically, such programmes have been provided within schools, for teachers, students, and sometimes for parents, and include information about: the extent of the problem of youth suicide; recognition of students at risk for suicidal behaviour; and referral and access to mental health resources within the community. In addition, some (few) programmes include courses to teach students coping skills, effective communication skills and management of stress in crisis situations.

Despite the recent proliferation of curriculum-based programmes, several reviews have raised a number of concerns:

1. School-based programmes may not reach a significant number of adolescents at risk for suicidal behaviour because these students are most likely to be those who terminate schooling early, truant, run away from home or are living in youth or detention centres.

2. In order to increase awareness and concern about the problem, the incidence and impact of youth suicide are sometimes exaggerated, increasing the risk that suicide may be perceived as more common than it is, and that suicidal behaviour may become "normalised" and more readily perceived as an acceptable option for teenagers facing stressful situations.

3. Too often, rather than suicide being presented as frequently occurring in people who have psychiatricillnesses, it is presented as an understandable response to adolescent stresses. Attempts to destigmatise suicide by suggesting that everyone is equally vulnerable to suicide when under stress misrepresent the important role of mental disorders. As Shaffer (1988a, p. 681) has commented, adolescents are less likely to imitate suicidal behaviour if suicide is presented as "a deviant act by someone with a mental disturbance". (Garland et al., 1989; Garland and Zigler, 1993; Shaffer et al., 1988a)

While there are concerns that school-based suicide prevention programmes directed at students might have unintended consequences, there is strong support for suicide prevention programmes, specifically for teachers and counsellors, which educate them about recognising students at risk for suicide and provide information about local mental health facilities to which they might refer such students. Shaffer et al. (1988b), for example, describe a two hour programme to educate teachers about indicators of suicide risk and community mental health resources which showed significant increases in participants' knowledge, and Reisman and Scharfman (1991) evaluated a series of six weekly education and training sessions for school personnel which resulted in significant changes in knowledge, attitudes and referral practices.

\section{Crisis intervention "hotline" services}

Crisis hotlines were established to give suicidal individuals the opportunity to talk to someone when they were in a crisis, in the hope that the suicide might be prevented (Schneidman and Farberow, 1965). Such hotlines are now available in most cities and refer callers to appropriate mental health services. To be effective these hotlines require trained operators, adequate backup services to whom callers can be referred urgently, and they depend upon callers complying with recommended follow-up advice (Shaffer et al., 1988a).

While there have been few evaluations of hotline services, there are suggestions that such services attract a population of mostly young females who tend not to access other mental health agencies (King, 1977), and that the provision of hotline services is associated with a reduction in suicide rates for young females (Miller, 1984). These findings imply that such services are unlikely to impact upon suicide rates for young males.

\section{Restriction of access to methods of suicide}

A frequent suggestion for suicide prevention is that access be restricted to potentially lethal methods of suicide, for example, by stricter gun control legislation or the introduction of clinically safer anxiolytic or hypnotic drugs. It seems unlikely that significant reductions in suicide rates will be achieved by the restriction of any one method of suicide while other methods remain available (Marzuk et al., 1992). Further, the extent to which preference for a particular method over-rides availability remains unclear. In general, restricting access to a method of suicide does not address the underlying issues of mental disorder or suicidal ideation.

\section{Postvention}

Postvention refers to the implementation, following a suicide, of various procedures for families, schools, workplaces and communities to limit the impact and effects of the suicide death. A variety of postvention efforts have been developed (Centres for Disease Control, 1992), but few have been adequately evaluated. 


\section{Publicity}

While there are clearly complex associations between publicity about suicide and imitative behaviours, the evidence thus far would appear to offer compelling support for the hypothesis that publicity about suicide may have unanticipated effects among vulnerable individuals who may model their behaviour upon accounts of suicide presented in the print or television media (Gould, 1990; Hazell, 1993). The need to minimise risks of such behaviour among vulnerable members of the community suggests a cautious approach to publicity should be adopted.

\section{Concluding comment}

In conclusion, it is disappointing to report that reviews of suicide prevention strategies produce no strong evidence for the efficacy of any current interventions. Too often, it seems, the various approaches being used have not been based on empirically-derived data, have failed to target high risk groups, have received inadequate evaluation and have little demonstrated efficacy. With the exception of family support programmes, and some curriculum-based programmes which include competency building components, few programmes attempt to offer additional support, alter life courses or offer long-term life changes which have been identified as the elements of effective programmes (Price et al., 1989).

\section{Implications for Educational Policies and Practices}

Although twice as many suicides in young people occur in the 20-24 year old age group compared to the 15-19 year old student group, schools have become a focus for suicide prevention efforts. There are a number of reasons for this. Firstly, schools are the only common setting for young people. Secondly, there are strong recommendations from a number of sources that new suicide prevention efforts should be part of existing services and, finally, it seems fiscally prudent to utilise the resources that schools provide.

These resources include the fact that teachers and counsellors feel that they have a responsibility to assist in the early identification and referral of students at risk of suicide and are willing to do so (Grob et al., 1983). Teachers and counsellors possess a great deal of practical experience with adolescents; they observe students regularly and are able to monitor changes in attendance, academic performance, behaviour or interactions with fellow students which may be indicators of distress.
However, some teachers and counsellors feel inadequately trained to carry out these tasks and to cope with students who have made suicide attempts (Mulder et al., 1989). Such concerns provide support for an intersectoral approach to suicide prevention in young people, as part of which community mental health teams would liaise with schools and regularly provide teachers with information, skills and support in dealing with suicidal students. A range of such programmes have been developed, predominantly in North America (Centres for Disease Control, 1992; Mulder et al., 1989) in which mental health personnel educate school staff about adolescent suicide; give information about risk factors and warning signs for suicide and about community sources for referral of students identified as being at risk for suicidal behaviour; teach skills for responding to and counselling such individuals; attempt to make staff aware of their own attitudes towards suicide and death and how these attitudes may influence responses to suicidal students; and assist staff to prepare a postvention plan to be available in the event of a student suicide. Such programmes have generally received positive responses from teachers (Centres for Disease Control, 1992) although more work remains to be done in programme development and evaluation.

There are further opportunities for schools to become involved in suicide prevention via the promotion of general mental health programmes, which aim to foster good mental health among students, together with the development of psychological and behavioural skills to make them more resistant to the development of psychopathology. Such programmes include the teaching of mental health education, self-awareness, coping skills, social skills and problem-solving skills and are broadly aimed at reducing vulnerability to a range of mental health problems, including depression, substance use and suicidal behaviour. While the effects of such programmes in achieving these outcomes are exceedingly difficult to assess, there appears to be at present widespread advocacy for replacing programmes with a specific focus (e.g., substance abuse, teenage pregnancy or suicide) with broader-based programmes aimed at improving mental health generally. The US Secretary of Health and Human Services Task Force on Youth Suicide recommended that "suicide prevention activities should be integrated into broader health promotion programmes and health care delivery services directed at preventing other self-destructive behaviours, such as alcohol and substance abuse, teen pregnancy and interpersonal violence" (Alcohol, Drug Abuse and Mental Health Administration, 1989, p. 3). 
Finally, schools have a role in postvention strategies which address the aftermath of suicidal behaviour. Based on his experience in New Zealand schools, Rivers (1995) has a series of recommendations for the preparation of appropriate management procedures for schools to follow in the event of a student suicide.

\section{Conclusion}

Suicide rates among young people, particularly young males, have increased markedly during the last few decades. While there are no clear reasons for this trend, major risk factors for suicidal behaviour have been identified and should be used to direct suicide prevention initiatives. The best opportunities to reduce suicide rates may lie in reducing the incidence of mental disorders among young people, and there are clear opportunities for schools to participate in such projects. While some reservations have been expressed about school suicide prevention programmes directed towards students, there appears to be strong support for prevention projects which aim to inform and support teachers and counsellors to better respond to students at risk of suicidal behaviour. There are clear calls for intersectoral approaches to address the issue of youth suicide with co-operative ventures between schools, communities and health services.

\section{References}

Alcohol, Drug Abuse and Mental Health Administration. (1989). Report of the Secretary's Task Force on Youth Suicide: Vol.1. Overview and recommendations. Washington, DC: US Government Printing Office.

Andrews, J. A. \& Lewinsohn, P. M. (1992). Suicidal attempts among older adolescents: Prevalence and co-occurrence with psychiatric disorders. Journal of the American Academy of Child and Adolescent Psychiatry, 31, 655-662.

Asberg, M., Nordstrom, P. \& Traskman-Bendz, L. (1986). Cerebrospinal fluid studies. In J. J. Mann \& M. Stanley (Eds.), Psychobiology of suicidal behaviour. New York: New York Academy of Sciences.

Beautrais, A. L., Joyce P. R. \& Mulder, R. T. Risk factors for serious suicide attempts among youth aged 13-24. Journal of the American Academy of Child and Adolescent Psychiatry (in press).

Beck, A.T., Weissman, A., Lester, D. et al. (1974). The measurement of pessimism: The Hopelessness Scale. Journal of Consulting and Clinical Psychology, 42, 861-865.
Brent, D. A., Perper, J. A., Goldstein, C. E., Kolko, D. J., Allan, M. J., Allman, C. J. \& Zelenak, J. P. (1988). Risk factors for adolescent suicide: A comparison of adolescent suicide victims with suicidal inpatients. Archives of General Psychiatry, 45, 581-588.

Brent, D.A., Perper, J.A., Moritz, G., Allman, C., Friend, A., Roth, C., Schweers, J., Balach, L. \& Baugher, M. (1993). Psychiatric risk factors for adolescent suicide: A case-control study. Journal of the American Academy of Child and Adolescent Psychiatry, 32, 521-529.

Centers for Disease Control. (1992). Youth suicide prevention programs: A resource guide. Atlanta: Centers for Disease Control.

D’Attilio, J. P., Campbell, B. M., Lubold, P., Jacobson, T. \& Richard, J. A. (1992). Social support and suicide potential: Preliminary findings for adolescent populations. Psychological Reports, 70, 76-78.

Diekstra, R. F. W. (1989). Suicidal behaviour in children and young adults: the international picture. Crisis, 10, 16-35.

Diekstra, R. F. W., Kienhorst, C. W. M. \& de Wilde, E. J. (1995). Suicide and suicidal behaviour among adolescents. In M. Rutter \& D. J. Smith (Eds.), Psychosocial disorders in young people: Time trends and their causes. Chichester: John Wiley \& Sons.

Dubow, E. F., Kausch, D. F., Blum, M. C., Reed, J. \& Bush, E. (1989). Correlates of suicidal ideation and attempts in a community sample of junior high and high school students. Journal of Clinical Child Psychology, 18, 158-166.

Farberow, N. L. (1991). Preparatory and prior suicidal behaviour factors. In L. Davidson \& M. Linnoila (Eds.), Risk factors for youth suicide. New York:Hemisphere.

Fergusson, D. M. \& Lynskey, M. T. (1995). Childhood circumstances, adolescent adjustment, and suicide attempts in a New Zealand birth cohort. Journal of the American Academy of Child and Adolescent Psychiatry, 34, 612-622.

Frances, A., Fyer, M. R. \& Clarkin, J. (1986). Personality and suicide. Annals of the New York Academy of Sciences, 487, 281-293.

Garland, A. F., Shaffer, D. \& Whittle, B. (1989). A national survey of school-based, adolescent suicide prevention programmes. Journal of the American Academy of Child and Adolescent Psychiatry, 28, 931-934.

Garland, A. F. \& Zigler, E. (1993). Adolescent suicide prevention: Current research and social policy implications. American Psychologist, 48, 169-182.

Gould, M., Wallenstein, S. \& Kleinman, M. H. (1990). Time-space clustering of teenage suicide. American Journal of Epidemiology, 131, 71-78. 
Grob, M. C., Klein, H. A. \& Eisen, S. V. (1983). The role of the high school professional in identifying and managing adolescent suicidal behaviour. Journal of Youth and Adolescence, 12, 163-173.

Hawton, K. \& Rose, N. (1986). Unemployment and attempted suicide among men in Oxford. Health Trends, 18, 29-32.

Hazell, P. (1993). Adolescent suicide clusters: Evidence, mechanisms and prevention. Australian and New Zealand Journal of Psychiatry, 27, 653-665.

Heikkinen, M. E., Isometsa, E. T., Aro, H. M., Sarna, S. J. \& Lonnqvist, J. K. (1995). Age-related variation in recent life events preceding suicide. Journal of Nervous and Mental Disease, 183, 325-331.

Joffe, R. T., Offord, D. R. \& Boyle, M. H. (1988). Ontario Child Health Study: Suicidal behaviour in youth aged 12-16 years. American Journal of Psychiatry, 145, 1420-1423.

Kety, S. (1986). Genetic factors in suicide. In A. Roy (Ed.), Suicide. Baltimore, MD:Williams and Wilkins.

Kienhorst, C. W. M., de Wilde, E. J., Diekstra, R. F. W. \& Wolters, W.H.G. (1992). Differences between adolescent suicide attempters and depressed adolescents. Acta Psychiatrica Scandinavica, 85, 222-228.

King, G. D. (1977). An evaluation of the effectiveness of a telephone counselling centre. American Journal of Community Psychology, 5, $75-83$.

Lesage, A. D., Boyer, R., Grunberg, F., Vanier, C., Morissette, R., Ménard-Buteau, C. \& Loyer, M. (1994). Suicide and mental disorders: A case-control study of young men. American Journal of Psychiatry, 151, 1063-1068.

Mann, J. J., Stanley, M., McBride, P. A. \& McEwen, B. S. (1986). Increased serotonin 2 and $B$-adrenergic receptor binding in the frontal cortices of suicide victims. Archives of General Psychiatry, 43, 954-959.

Marttunen, M., Aro, H., Henriksson, M. \& Lonnqvist, J. (1991). Mental disorder in adolescent suicide: DSM-III-R Axes I and II among 13 to 19 year olds. Archives of General Psychiatry, 48, 834-839.

Marzuk, P. M., Leon, A. C., Tardiff, K., Morgan, E. B., Stajic, M. \& Mann, J. J. (1992). The effect of access to lethal methods of injury on suicide rates. Archives of General Psychiatry, 49, 451-458.

Meehan, P. J., Lamb, J. A., Saltzman, L. E. \& O'Carroll, P. W. (1992). Attempted suicide among young adults: Towards a meaningful estimate of prevalence. American Journal of Psychiatry, 149, 41-44.

Miller, H. L., Coombs, D.W., \& Leeper, J. D. et al. (1984). An analysis of the effects of suicide prevention facilities on suicide rates in the United States. American Journal of Public Health, 74, 340-343.
Moscicki, E. K. (1995). Suicide in childhood and adolescence. In F. C. Verhulst \& H. M. Koot (Eds.), The epidemiology of child and adolescent psychopathology. Oxford: University Press

Mulder, A. M., Methorst, G. J. \& Diekstra, R. F. W. (1989). Prevention of suicidal behaviour in adolescents: The role and training of teachers. Crisis, 10, 36-51.

Neuringer, C. (Ed.) (1974). Psychological assessment of suicidal risk. Springfield, IL: Charles C. Thomas.

New Zealand Health Information Service. (1995a). Selected morbidity and hospital data - Vol. 1 1993. Wellington: Ministry of Health.

New Zealand Health Information Service. (1995b). Mortality and demographic data 1993. Wellington: Ministry of Health.

Patsiokas, A. T., Clum, G. A. \& Luscomb, R. L. (1979). Cognitive characteristics of suicide attempters. Journal of Consulting and Clinical Psychology, 47, 478-484.

Petronis, K. R., Samuels, J. F., Moscicki, E. K. \& Anthony, J. C. (1990). An epidemiologic investigation of potential risk factors for suicide attempts. Social Psychiatry and Psychiatric Epidemiology, 25, 193-199.

Platt, S., Kreitman, N. (1984). Trends in parasuicide and unemployment among men in Edinburgh, 1968-82. British Medical Journal, 289, 1029-1032.

Price, R. H., Cowen, E. L., Lorion, R. P. \& Ramos-McKay, J. (1989). The search for effective prevention programs: What we learned along the way. American Journal of Orthopsychiatry, 59, 49-58.

Reisman, B. A. \& Scharfman, M. A. (1991). Teenage suicide prevention workshops for guidance counsellors. Douglaston, NY: Pride of Judea Mental Health Centre.

Rich, C. L., Fowler, R. C., Fogarty, L. A. \& Young, D. (1988). San Diego suicide study III: Relationships between diagnoses and stressors. Archives of General Psychiatry, 45, 589-592.

Rivers, L. (1995), Young person suicide. Wellington, New Zealand: Special Education Service.

Roy, A. (1983). Family history of suicide. Archives of General Psychiatry, 40, 971-974.

Roy, A., Segal, N. L., Centerwall, B. S. \& Robinette, C. D. (1991). Suicide in twins. Archives of General Psychiatry, 48, 29-32.

Runeson, B. (1989), Mental disorder in youth suicide. Acta Psychiatrica Scandinavica, 79, 490-497.

Sainsbury, P., Jenkins, J. \& Baert, A. E. (1981). Suicide trends in Europe. Copenhagen: WHO. 
Schneidman, E. S. \& Farberow, N. L. (1965). The Los Angeles suicide prevention centre: A demonstration of public health feasibilities. American Journal of Public Health, 55, 21-26.

Shaffer, D. (1974). Suicide in childhood and early adolescence. Journal of Child Psychology and Psychiatry, 15, 275-291.

Shaffer, D., Garland, A., Gould, M., Fisher, P. \& Trautman, P. (1988a). Preventing teenage suicide: A critical review. Journal of the American Academy of Child and Adolescent Psychiatry, 27, 675-687

Shaffer, D., Garland, A., Whittle, B. \& Underwood, M. (1988b). An evaluation of three adolescent suicide prevention programs. Trenton: New Jersey Governor's Council on Adolescent Suicide.

Shaffer, D. \& Piacentini, J. (1994). Suicide and attempted suicide. In M. Rutter, E. Taylor \& L. Hersow (Eds.), Child and adolescent psychiatry. Oxford: Blackwell.

Shaffer, D., Gould, M. \& Hicks, R. C. (1994). Worsening suicide rate in black teenagers. American Journal of Psychiatry, 151, 1810-1812.

Shafii, M., Carrigan, S., Whitinghill, J. R. \& Derrick, A. (1985). Psychological autopsy of completed suicide in children and adolescents. American Journal of Psychiatry, 142, 1061-1064.

Shepherd, D. M. \& Barraclough, B. M. (1980). Work and suicide: An empirical investigation. British Journal of Psychiatry, 136, 469-478.

Skegg, K., Cox, B. \& Broughton, J. (1995). Suicide among New Zealand Maori: Is history repeating itself? Acta Psychiatrica Scandinavica, 92, 453-459.

Smith, K. \& Crawford, S. (1986), Suicidal behaviour among "normal" high school students. Suicide and Life-Threatening Behaviour, 16, 313-325.

Spirito, A., Brown, L., Overholser, J. \& Fritz, G. (1989). Attempted suicide in adolescence: A review and critique of the literature. Clinical Psychology Review, 9, 335-363.

World Health Organisation. (1993). World Health Statistics Annual. Geneva: WHO.

\section{The author}

Annette Beautrais is the Principal Investigator with the Canterbury Suicide Project in Christchurch. The project, which began in 1991, consists of a case control study of completed suicide and serious attempted suicide, and a follow-up study of individuals who have made serious suicide attempts. The study is funded by the Health Research Council. 